\title{
Decaying Hardwood Associated Fungi Showing Signatures of Polyethylene Degradation
}

\author{
Prameesha Perera, ${ }^{a}$ Anushi Suwanethya Deraniyagala, ${ }^{\mathrm{a}, \mathrm{b}}$ Maduri Piumi \\ Sashikala Mahawaththage, ${ }^{\text {a,c }}$ Harshini Herath, ${ }^{\mathrm{a}}$ Chandima Shashikala Kumari Rajapakse, ${ }^{\mathrm{d}}$ \\ Priyanga Wijesinghe, ${ }^{\mathrm{e}}$ and Renuka Nilmini Attanayake ${ }^{\mathrm{a}, *}$
}

\begin{abstract}
The involvement of wood decay fungi and the importance of their enzymes in polyethylene degradation is well documented. Therefore, decayresistant hardwood associated fungi should be better degraders with their versatile enzymatic systems. In the current study, decaying hardwood associated fungi were isolated and their ability to degrade low-density polyethylene (LDPE) was assessed. Thirty-three isolates were identified by sequencing the internal transcribed spacer region of nuclear ribosomal DNA. Randomly selected isolates were tested for laccase producing abilities. Three species were selected to test their potentials in LDPE sheet degradation. Fungi were incubated in Czapek-Dox broth containing 20micron LDPE sheets at room temperature for 60 days. The biodegradation signatures were assessed by analyzing the changes in structural characteristics of LDPE using Fourier transform infrared spectroscopy (FTIR), scanning electron microscopy (SEM), percent reduction of tensile properties, and weight loss. FTIR analysis revealed changes in certain functional groups compared with the control, indicating chemical changes resulting from the treatment. LDPE sheets incubated with fungi showed cracks and holes under SEM analysis, percent reduction in tensile properties, and weight loss, which are the signatures of degradation. This study revealed that the hardwood decaying basidiomycetes, Phlebiopsis flavidoalba, Schizophyllum commune, and Phanerodontia chrysosporium have the potential for in vitro LDPE degradation.
\end{abstract}

Keywords: Polyethylene; LDPE; Fungi; Biodegradation; Laccase

Contact information: a: Department of Plants and Molecular Biology, University of Kelaniya, 11600, Sri Lanka; b: Collage of Agricultural and Environmental Sciences, University of Georgia, 2360 Rainwater Road, Tifton, GA 31793; c: School of Biosciences, University of Melbourne, Victoria 3010 Australia, d: Department of Chemistry, University of Kelaniya, 11600, Sri Lanka; e: Department of Botany, University of Peradeniya, 20400, Sri Lanka; *Corresponding author: renuka@kln.ac.lk

\section{INTRODUCTION}

Wood decay is an important process in forest ecosystems. Although many organisms such as beetles, flies, slime molds, bacteria, slugs, and snails are directly or indirectly involved in wood decay, fungi play the primary role. Among diverse groups of wood decay fungi, white-rot causing basidiomycetes are particularly evolved to degrade cellulose, hemicellulose, and the strongest natural polymer, lignin, present in hardwoods. Though lignin is comprised of three types of phenyl-propane units (six-carbon rings with three-carbon side chains) bonded to one another in approximately 12 different ways, whiterot fungi can break down this complex polymer using only a few versatile enzymes (Kirk and Farrell 1987). They secrete major lignin modifying enzyme families such as lignin peroxidase, manganese peroxidase, versatile peroxidase, and laccase (Hatakka 1994;

Perera et al. (2021). "Fungal polyethylene degraders," BioResources 16(4), 7056-7070. 7056 
Nicolcioiu et al. 2018; Kumar and Chandra 2020). Among these enzymes, laccases produced by white-rot basidiomycetes have high redox potential and diverse catalytic properties compared with the laccases from plants and bacteria (Rodgers et al. 2010). Therefore, fungal laccases are considered as multipurpose biocatalysts having various biotechnologically important properties, i.e., polyethylene degradation and industrial dye decolorization (Santo et al. 2013; Mate et al. 2016; Han et al. 2021).

With the rapid industrialization, polyethylene has become an essential item in day to-day life. However, due to its durability and decay resistance nature, the accumulation of polyethylene is a serious environmental concern. Even though polyethylene is resistant to degradation due to its hydrophobicity, high water repellency, and lack of functional groups that are prone to hydrolytic cleavage by the microbial enzymes (Chiellini et al. 2003), involvement of microorganisms, especially fungi in polyethylene degradation has been reported (Romero et al. 2007; Mathur et al. 2011; Ojha et al. 2017). In fact, there is a relationship between polyethylene degradation and lignolytic activity of white-rot bassidiomycetes (Iiyoshi et al. 1998; Krueger et al. 2015).

Polyethylene biodegradation takes place via extracellular enzymes that degrade complex polymers to short chain or smaller molecules, which cross microbial membranes (Gu 2003). Several studies have assessed polyethylene degradation abilities of various microorganisms using scanning electron microscopy (SEM), Fourier transform infrared spectroscopy (FTIR), and reduction in tensile properties and weight (Mahalakshmi et al. 2012; Das and Kumar 2015; Ojha et al. 2017; Kang et al. 2019). Very recently, Spina et al. (2021) used SEM and FTIR analysis and reprted by filamentous fungal involvement in untreated low density polyethylene (LDPE) degradation.

As one of the world's biodiversity hotspots, Sri Lanka has diverse fungal taxa, which are not fully explored. The dry zone forests of the country are rich in decay-resistant, hardwood-bearing plant species such as Diospyros ebenum (Ebony), Azadirachta indica (Neem), and Manilkara hexandra (iron wood), and culturable fungal species associated with these decaying hardwoods are not yet thoroughly studied. These fungal species may be good ligninase producers that could degrade various polymers including polyethylene. The objectives of the present study were to isolate and identify culturable fungal species associated with decaying hardwoods from a Sri Lankan dry zone forest reserve and to assess polyethylene degradation abilities of selected laccase producers. Culturable fungal species were identified by barcoding the internal transcribed spacer region (ITS) of nuclear ribosomal DNA (rDNA-ITS) region, and three selected species were tested for their polyethylene degradation abilities. While Phlebiopsis flavidoalba was the most promising species, Schizophyllum commune and Phanerodontia chrysosporium also showed signatures in LDPE degradation.

\section{EXPERIMENTAL}

\section{Sample Collection and Isolation of Fungi}

Decaying hardwood samples $(n=30)$ were collected from secondary forest region of the Dimbulagala dry mixed evergreen forest reserve, Sri Lanka, in 2018. Wood samples were sealed in polyethylene bags, air dried, and stored at room temperature. Decaying wood pieces $(5.0 \mathrm{~mm} \times 5.0 \mathrm{~mm})$ were surface sterilized with $70 \%$ ethanol for $3 \mathrm{~min}$, followed by three serial washings with sterilized distilled water. Sterilized wood pieces were blot dried aseptically, trimmed from the sides, and placed on two types of media: 
Potato Dextrose Agar (PDA) amended with streptomycin $(100 \mu \mathrm{g} / \mathrm{mL})$ and PDA amended with both streptomycin $(100 \mu \mathrm{g} / \mathrm{mL})$ and fungicide carbendazim $(4 \mu \mathrm{g} / \mathrm{mL})$, modified from Baumgartener et al. (2010). Petri plates were incubated at room temperature for three to seven days. All fungal colonies were sub-cultured, and pure cultures were obtained. Isolates were labelled based on the sampling location, season, and the attempt of isolation: D-Dimbulagala, A- arid or dry season sampling, W- wet season sampling followed by the isolation attempts and colony numbers. In the case of isolate $\mathrm{KH} 2 \_1$, because the host plant is known as Azadirachta indica (English - Neem and Local name - Kohomba), it was also taken into the account when assigning a code.

\section{Identification of Fungal Species}

The colony morphology of all isolated fungal samples was observed. Microscopic features of the isolates were observed under a light microscope, and photographs were taken. Fungal genomic DNA was isolated according to the CTAB protocol with some modifications (Maduranga et al. 2018) and stored at $-20^{\circ} \mathrm{C}$.

Polymerase chain reaction (PCR) was conducted with universal ITS primers (White et al. 1990) to amplify the rDNA-ITS region. The PCR mixture consisted of 1x Colorless GoTaq ${ }^{\circledR}$ Flexi Buffer, $2 \mathrm{mM} \mathrm{MgCl} 2,10 \mathrm{mM}$ each $\mathrm{dNTP}, 0.5 \mu \mathrm{M}$ forward and reverse primers, 1.25U of GoTaq® DNA polymerase (Promega Inc., Madison, WI, USA), and < $0.5 \mu \mathrm{g}$ template DNA. The PCR program was as follows: initial denaturation at $95{ }^{\circ} \mathrm{C}$ for 4 min, 40 cycles of denaturation at $94{ }^{\circ} \mathrm{C}$ for 30 seconds, annealing $55^{\circ} \mathrm{C}$ for 30 seconds, extension at $72{ }^{\circ} \mathrm{C}$ for 30 seconds, and final extension at $72{ }^{\circ} \mathrm{C}$ for $10 \mathrm{~min}$ (Veriti ${ }^{\circledR} 96$ Well Thermal Cycler, ABI Biosystems, Foster City, CA, USA). Pure PCR products were outsourced for Sanger sequencing at Genetech institute, Colombo, Sri Lanka. Sequences were manually edited using BioEdit sequence Alignment Editor (Version 7.2, Hall 1999) and compared with the vouched or published records of the National Center for Biotechnology Information (NCBI) database using Basic Local Alignment Search Tool (BLAST). The sequences were deposited in the GenBank, and accession numbers were obtained. Isolates used in the present study are shown in Table 1.

\section{Qualitative Assessment of Laccase Production}

A subset of 20 isolates representing mostly basidiomycetes were selected for qualitative assay of laccase production. PDA plates amended with $0.01 \%$ guaiacol (G5502, Sigma, St Louis, MO, USA) were prepared (G-PDA) and inoculated with an actively growing mycelial disk (5 mm diam.) of each fungal culture (Swe 2011; Nicolcioiu et al. 2018). Plates were incubated at room temperature for 5 to 7 days, and a color change from colorless to reddish brown was recorded. Plates were arranged in completely randomized design (CRD) with 3 replicates per isolate, and 3 replications of the whole experiment.

\section{Ability of Selected Laccase Producers to Grow in Wood Amended Agar}

Out of the 20 isolates, four fungal isolates that produced the strongest reddish brown coloration on G-PDA plates were tested for the ability to grow on wood amended agar following Cortina-Escribano et al. (2020) with minor modifications. Wood agar was prepared using a commercially available hardwood, Swietenia macrophylla (Mahogany) saw dust or wood chips. Wood chips were ground, sieved through $0.2 \mathrm{~mm}$ mesh, and amended with agar. Wood agar plates were inoculated using a mycelial disc $(5.00 \mathrm{~mm}$ diam.) obtained from the actively growing edge of 7 to 10-day old cultures in triplicates. Plates were incubated at the room temperature $\left(31 \pm 0.5^{\circ} \mathrm{C}\right)$ in completely randomized 
design, and colony diameters were measured after 3, 5, and 7 days incubation. Significant difference in colony diameters were determined.

\section{Screening for Low Density Polyethylene (LDPE) Degradation}

From the above four isolates that produced stronger reddish brown color in G-PDA plate assay, three isolates belonging to three different species were subjected to LDPE degradation assay (Ojha et al. 2017). Briefly, sterilized 20-micron LDPE sheets (2 cm x 10

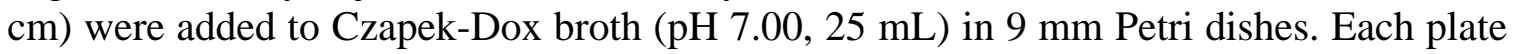
was inoculated with three mycelial disks $(5 \mathrm{~mm}$ diam.) obtained from actively growing edges of each fungal culture plate and incubated for 60 days at room temperature with three replicates per isolate. LDPE sheets colonized with mycelia were washed with $70 \%$ ethanol followed by three serial washings with sterilized distilled water to remove attached mycelial mats. Stripes were air dried followed by drying in a desiccator for one day. Control plates were maintained without fungal inoculum. FTIR spectra of all stripes were recorded (PerkinElmer FTIR C107062, Waltham, MA, USA) using the attenuated total reflection (ATR) method. The FTIR spectra obtained for inoculated LDPE stripes were compared with the FTIR spectrum of untreated LDPE strips (control) to determine the specific structural changes during biodegradation. From each treatment, samples were taken from the edges as well as from the middle of the polyethylene sheets to determine if the sampling site has any effect on the data. LDPE samples were placed on the diamond crystal plate, and the spectra were recorded from 400 to $4000 \mathrm{~cm}^{-1}$ at a resolution $1 \mathrm{~cm}^{-1}$ with 32 scans.

The weight of LDPE sheets was obtained using a high-sensitive four-digit analytical balance before and after the treatments, and percent weight changes were computed using Eq. 1. Significant differences in percent weight loss were determined.

$$
\text { Weight loss }(\%)=\frac{(\text { Initial weight-final weight) }}{\text { Initial weight }} \times 100
$$

The mechanical properties of polymeric films such as percentage loss of maximum tensile stress and tensile stress at yield were determined following Munir et al. (2018) using a universal testing machine (UTM) (Instron 3365 Tensile Tester, MA, USA). Treated LDPE sheets of $6 \mathrm{~cm} \times 1 \mathrm{~cm}$ were subjected to $20 \mathrm{~mm} \mathrm{~min}^{-1}$ elongation. The instrument offers a testing rate range from 0.01 to $1000 \mathrm{~mm} \mathrm{~min}^{-1}$ along with a force capability of 5 $\mathrm{kN}$. Young's modulus was calculated for each sample using tensile stress and strain data and compared with the controls (Samanta et al. 2020). Significant difference in reduction of mechanical properties were determined.

Scanning electron microscopy was performed with a Hitachi SU6600 Analytical Variable Pressure FE-SEM (Tokyo, Japan) for all samples. LDPE sheets were washed and dried, cut into $0.5 \mathrm{~cm} \times 0.5 \mathrm{~cm}$ pieces, and then mounted on the stub using carbon tapes. The samples were sputtered with gold particles $(5$ to $10 \mathrm{~nm})$ for 15 seconds inside the ion sputter (Ion Sputter E-1010, Tokyo, Japan). Physical changes such as the formation of cracks and holes were observed under $10 \mathrm{kV}$ in both control and treated LDPE sheets.

\section{Statistical Analysis}

In each experimnet, experimental units were in triplicates and arranged in completely randomized design. Significant differneces among treatments were determined by one-way ANOVA using Minitab 17 statistical software (State College, PA, USA) 


\section{RESULTS AND DISCUSSION}

This study reports promising and potential polyethylene degraders, P. flavidoalba, $S$. commune, and $P$. chrysosporium, which inhabit decaying hardwoods in Sri Lanka. ITSrDNA sequencing was used to identify fungal species (Table 1) because it has the highest probability of accurate fungal species identification (Schoch et al.2012), and the databases are rich with vouchered ITS sequence information (Nilsson et al. 2019). Even though multigene phylogeny based species concept is more suitable for fungal species delineation, the current research was not in the line of molecular phylogeny of fungi. Out of 40 isolates, 33 were identified up to the species level using rDNA-ITS sequence results in combination with morphological traits (Fig. 1) and vouchered in the culture collection of the Department of Plant and Molecular Biology, University of Kelaniya, Sri Lanka. The rest of the isolates either failed in PCR amplification of continuous attempts, or germination was lost during the subsequent sub culturing process. When isolating fungi associated with decaying hardwood, fast-growing commoners such as Trichoderma spp. and Lasiodiplodia spp. were frequently observed on PDA. PDA media amended with an antibiotic and a fungicide, carbendazim, helped in capturing other fungal genera.
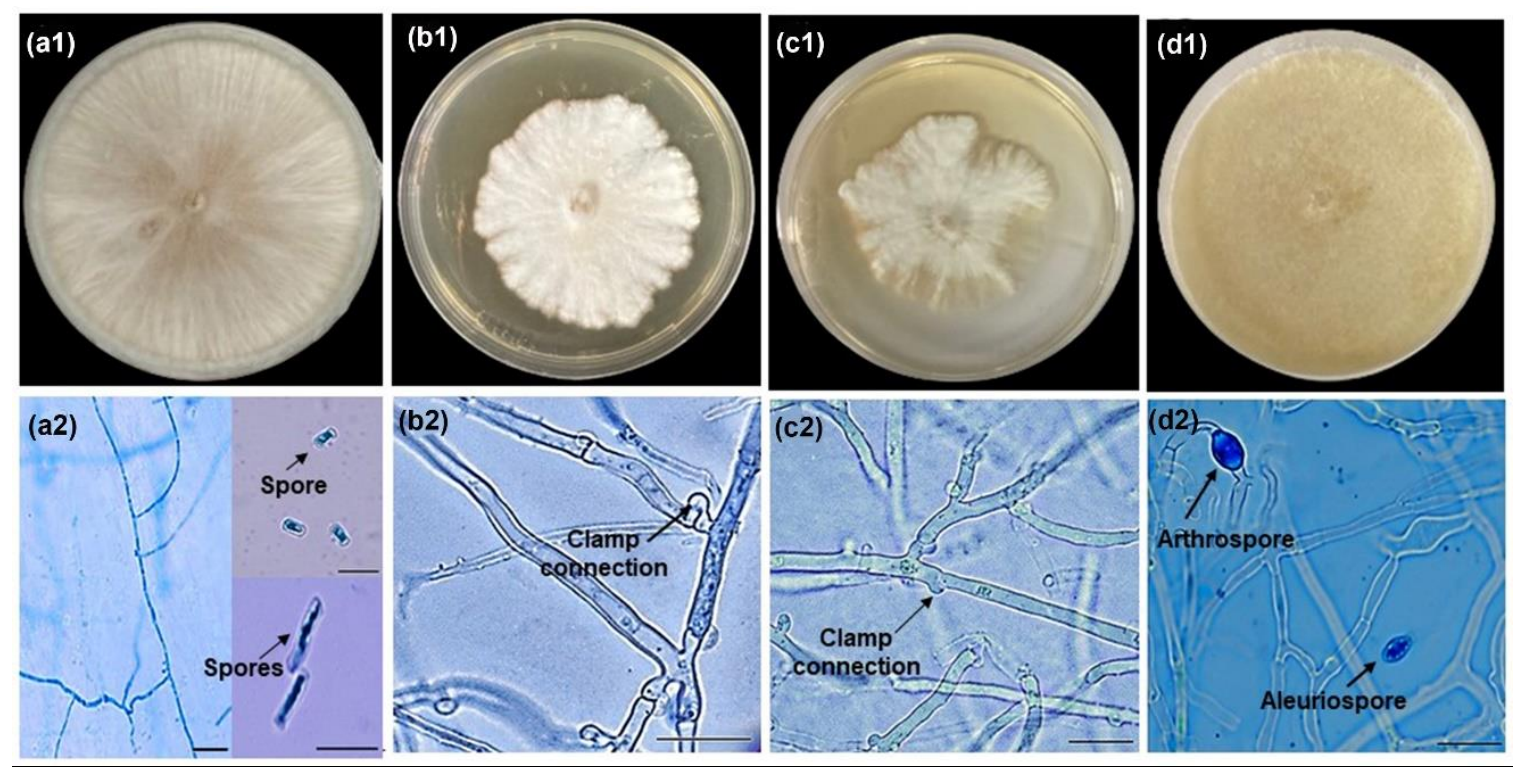

Fig. 1. Colony morphology and microscopic features of fungal species. (a1, a2) Phlebiopsis flavidoalba (KH2_1), (b1, b2) Schizophyllum commune (DPW_1), (c1-c2) S. commune (DLP_1), and (d1,d2) Phanerodontia chrysosporium (DBP). All scale bars represent $20 \mu \mathrm{m}$.

\section{Qualitative Assessment of Laccase Production}

Reddish brown color development in the PDA medium containing guaiacol (GPDA) was used as a qualitative test for laccase production (Nicolcioiu et al. 2018).

Out of 20 isolates selected, 13 produced reddish brown color on G-PDA plates consistently (Fig. 2 and Table 1). Guaiacol, was used as the oxidation-indicator substrate for rapid screening of laccase producers. The reddish brown color is formed by oxidizing reactions, resulting in the production of quinone (Kiiskinen et al. 2004; Ravichandran et al. 2019). 

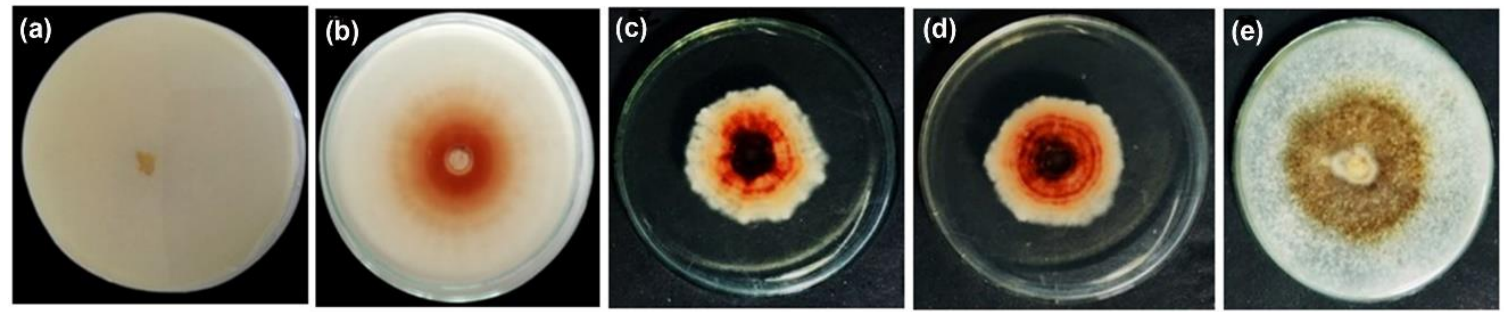

Fig. 2. Guaiacol oxidation in G-PDA medium after 7 days of inoculation. Formation of reddish brown color ring indicate the presence of laccase. (a) Control- laccase non-producer, (b) Phlebiopsis flavidoalba (KH2_1), (c) Schizophyllum commune (DPW_1), (d) S. commune (DLP_1), and (e) Phanerodontia chrysosporium (DBP).

Table 1. Isolate Codes, their GenBank Accession Numbers, Species Identity, and Laccase Producing Abilities as Shown in Guaiacol Amended PDA Plates (GPDA)

\begin{tabular}{|c|c|c|c|c|c|}
\hline Number & Isolate Code & $\begin{array}{c}\text { GenBank } \\
\text { Accession }\end{array}$ & Species* $^{*}$ & $\begin{array}{l}\text { Percent } \\
\text { Similarity }\end{array}$ & $\begin{array}{l}\text { Reaction } \\
\text { in G-PDA }\end{array}$ \\
\hline 1 & DBF & MF185103 & $\begin{array}{c}\text { Daldinia eschscholtzii } \\
\text { (KY432354.1) }\end{array}$ & $100 \%$ & + \\
\hline 2 & DB8 & MF671949 & $\begin{array}{c}\text { Lasiodiplodia crassispora } \\
\text { (JX464058.1) }\end{array}$ & $99 \%$ & + \\
\hline 3 & DW9 & MF671950 & $\begin{array}{c}\text { Trichoderma erinaceus } \\
\text { (MG372128.1) }\end{array}$ & $99 \%$ & + \\
\hline 4 & DPW_1 & MZ087903 & $\begin{array}{c}\text { Schizophyllum commune } \\
\text { (MH857808.1) }\end{array}$ & $99 \%$ & ++ \\
\hline 5 & DZF4A & MF195026 & $\begin{array}{c}\text { Coprinellus } \\
\text { aureogranulatus } \\
\text { (MH379152.1) }\end{array}$ & $99 \%$ & + \\
\hline 6 & TW2AWP & MF195028 & $\begin{array}{l}\text { Gymnopilus dilepis } \\
\text { (KT368680.1) }\end{array}$ & $99 \%$ & + \\
\hline 7 & DHF2 & MF289184 & $\begin{array}{c}\text { Perenniporia tephropora } \\
\text { (JN048763.1) }\end{array}$ & $98 \%$ & + \\
\hline 8 & ADW2A & MF289185 & $\begin{array}{c}\text { Coriolopsis caperata } \\
\text { (KR078279.1) }\end{array}$ & $99 \%$ & + \\
\hline 9 & ADW3 & MF289186 & $\begin{array}{c}\text { Phanerochaete australis } \\
\text { (KP135080.1) }\end{array}$ & $98 \%$ & + \\
\hline 10 & $\mathrm{KH} 2 \_1$ & MZ087901 & $\begin{array}{c}\text { Phlebiopsis flavidoalba } \\
\text { (MT386377.1) }\end{array}$ & $99 \%$ & ++ \\
\hline 11 & DLP_1 & MZ087904 & $\begin{array}{c}\text { Schizophyllum commune } \\
\text { (MH857808.1) }\end{array}$ & $99 \%$ & ++ \\
\hline 12 & DBP & MZ087900 & $\begin{array}{l}\text { Phanerodontia } \\
\text { chrysosporium }\end{array}$ & $99 \%$ & ++ \\
\hline 13 & WDF 08 & MZ087909 & $\begin{array}{l}\text { Phanerochaete } \\
\text { pseudomagnoliae } \\
\text { (KP135091.1) }\end{array}$ & $98 \%$ & + \\
\hline 14 & DDW10A_1 & MZ087902 & $\begin{array}{c}\text { Fusarium pseudensiforme } \\
\text { (MH863652.1) }\end{array}$ & $99 \%$ & $-a$ \\
\hline 15 & DHF5B_1 & MZ087907 & $\begin{array}{c}\text { Fusarium decemcellulare } \\
\text { (FN667579.1) }\end{array}$ & $99 \%$ & $-a$ \\
\hline 16 & GDF01 & MZ087911 & $\begin{array}{c}\text { Curvularia papendorfii } \\
\text { (KC592365.1) }\end{array}$ & $99 \%$ & - \\
\hline 17 & WDF02HY & MZ087908 & $\begin{array}{c}\text { Coprinellus } \\
\text { radians (KT828727.1) }\end{array}$ & $99 \%$ & - \\
\hline 18 & DZFK2_1 & MZ087906 & Fusarium pseudensiforme & $99 \%$ & $-a$ \\
\hline
\end{tabular}




\begin{tabular}{|c|c|c|c|c|c|}
\hline & & & (MH863652.1) & & \\
\hline 19 & ADB2 & MF671942 & $\begin{array}{c}\text { Trichoderma harzianum } \\
\text { (KT852806.1) }\end{array}$ & $99 \%$ & - \\
\hline 20 & ADB5 & MF671944 & $\begin{array}{c}\text { Trichoderma harzianum } \\
\text { (KT852806.1) }\end{array}$ & $99 \%$ & - \\
\hline 21 & ADW5 & MF671947 & $\begin{array}{c}\text { Trichoderma harzianum } \\
\text { (KF201295.1) }\end{array}$ & $99 \%$ & $n / d$ \\
\hline 22 & ADB2A & MF671989 & $\begin{array}{c}\text { Trichoderma harzianum } \\
\text { (KT852833.1) }\end{array}$ & $100 \%$ & $n / d$ \\
\hline 23 & DDW6 & MF671993 & $\begin{array}{c}\text { Trichoderma } \\
\text { Iongibrachiatum } \\
\text { (KJ174214.1) }\end{array}$ & $99 \%$ & $n / d$ \\
\hline 24 & ADB7 & MF671945 & $\begin{array}{c}\text { Lasiodiplodia crassispora } \\
\text { (HM466955.2) }\end{array}$ & $99 \%$ & $n / d$ \\
\hline 25 & ADB4 & MF671943 & $\begin{array}{c}\text { Lasiodiplodia crassispora } \\
\text { (FJ888477.1) }\end{array}$ & $98 \%$ & $n / d$ \\
\hline 26 & DW7 & MF671996 & $\begin{array}{c}\text { Lasiodiplodia crassispora } \\
\text { JX464058.1) }\end{array}$ & $99 \%$ & $n / d$ \\
\hline 27 & ADB3 & MF671990 & $\begin{array}{c}\text { Xylogone sphaerospora } \\
\text { (GQ272626.1) }\end{array}$ & $98 \%$ & $n / d$ \\
\hline 28 & DDW2 & MF671991 & $\begin{array}{c}\text { Neoscytalidium hyalinum } \\
\text { (MH861121.1) }\end{array}$ & $99 \%$ & $n / d$ \\
\hline 29 & DDW10C & MF671995 & $\begin{array}{c}\text { Hypoxylon fragiforme } \\
\text { (KJ826511.1) }\end{array}$ & $98 \%$ & $n / d$ \\
\hline 30 & DYF & MF164877 & $\begin{array}{c}\text { Lentinus squarrosulus } \\
\text { (KT273373.1) }\end{array}$ & $99 \%$ & $n / d$ \\
\hline 31 & DW11 & MF671952 & $\begin{array}{c}\text { Phialophora alba } \\
\text { (HM116755.1) }\end{array}$ & $99 \%$ & $n / d$ \\
\hline 32 & DDW5 & MF671992 & $\begin{array}{c}\text { Pleurostoma richardsiae } \\
\text { (MH859458.1) }\end{array}$ & $99 \%$ & $n / d$ \\
\hline 33 & DDW10B & MF671994 & $\begin{array}{c}\text { Paecilomyces formosus } \\
\text { (MH859718.1) }\end{array}$ & $99 \%$ & $n / d$ \\
\hline
\end{tabular}

Note: *, GenBank accession of authenticated sequence with the highest similarity; +, Color change into reddish brown in G-PDA plates, -, no color change; n/d, not determined. Isolate codes indicate the followings; D-Dimbulagala (Sampling location), A- arid or dry season sampling, W- wet season sampling, G- grass land area and the numbers represent isolation attempts and colony numbers. ${ }^{a}$ cultures had a red coloration in both PDA and GPDA and tentatively indicated as negative, ++ strongest colore recion on G-PDA plates.

Table 2. Comparison of Colony Diameters ( \pm SD) of Fungi on Swietenia macrophylla Saw Dust Amended Agar and Percent Reduction in Weight of LDPE Sheets

\begin{tabular}{|c|c|c|c|c|}
\hline \multirow{2}{*}{ Isolate Name } & \multicolumn{3}{|c|}{ Colony Diameter $(\mathrm{cm}) \pm \mathrm{SD}$} & \multirow{2}{*}{$\begin{array}{c}\text { \% Reduction } \\
\text { in Weight } \pm \\
\text { SD }\end{array}$} \\
\hline & 3 Days & 5 Days & 7 Days & \\
\hline Phlebiopsis flavidoalba (KH2_1) & $3.4 \pm 0.4^{a}$ & $6.0 \pm 0.3^{a}$ & $7.2 \pm 0.3^{b}$ & $2.6 \pm 1.51$ \\
\hline Schizophyllum commune (DPW_1) & $1.3 \pm 0.1^{c}$ & $4.0 \pm 0.1^{c}$ & $5.1 \pm 0.1^{d}$ & $\mathrm{n} / \mathrm{d}$ \\
\hline Schizophyllum commune (DLP_1) & $1.2 \pm 0.1^{c}$ & $3.9 \pm 0.2^{c}$ & $6.1 \pm 0.1^{c}$ & $9.65 \pm 1.52$ \\
\hline Phanerodontia chrysosporium (DBP) & $2.3 \pm 0.2^{b}$ & $5.2 \pm 0.3^{b}$ & $7.8 \pm 0.1^{a}$ & $2.5 \pm 1.51$ \\
\hline
\end{tabular}

Means followed by different superscript letters within a column are significantly different $(p<0.05)$ $\mathrm{n} / \mathrm{d}$ : not determined 


\section{The Ability of Fungi to Grow on Wood Dust Amended Agar}

Four of the strongest reddish brown color producers (KH2_1, DPW_1, DLP_1, DBP) were subjected to wood agar assay. To ensure that the fungal isolates used in LDPE degradation experiments could grow in wood containing media, wood dust of a longlasting, decay-resistant, and commercially available $S$. macrophylla was used. There was a significant difference among fungal species in colony diameters on wood dust amended media (Table 2). This confirms that the selected isolates generated from the decaying hardwoods are able to utilize hardwood.

\section{Screening of Polyethylene Biodegradation}

Biodegradation is the process of complete mineralization of the intact, pristine polymers. It takes place in four stages; biodeterioration, biofragmnetation, bioassimilation, and mineralization (Muhonja et al. 2018; Montazer et al. 2020). During biodeterioration, structural changes of the polymer result, creating access points for microbial enzymes (Montazer et al. 2020). Such structural changes are considred as the initial signatures of biodegradation. In the present study, after the incubation period, mycelial growth of selected fungal species at the edges of polyethylene sheets was observed. Signatures of polyethylene degradation are assessed by several methods: analyzing FTIR spectra, percent reduction in weight and tensile properties, and SEM analysis (Gulmine et al. 2002; Gajendiran et al. 2016; Bombelli et al. 2017). FTIR spectroscopy assesses the structural changes including the formation or disappearance of functional groups on the surface of a polymer upon microbial degradation (Jung et al. 2018). The FTIR spectra of LDPE films after 60 days of incubation are shown in Fig. 3. The appearance of new peaks, along with the disappearance and shifting of peaks attributed to the stretching and bending vibrations of different functional groups-confirmed the structural changes that occurred on the polymer surface upon biodegradation by $P$. flavidoalba (KH2_1), S. commune (DLP_1), and $P$. chrysosporium (DBP).

The prominent peaks of LDPE occurring at 2915 and $2847 \mathrm{~cm}^{-1}$ were attributed to asymmetric and symmetric $\mathrm{C}-\mathrm{H}$ stretching, respectively. A peak at $1462 \mathrm{~cm}^{-1}$ was attributed to $\mathrm{C}-\mathrm{H}$ bending of $\mathrm{CH}_{2}$, and a peak at $718 \mathrm{~cm}^{-1}$ was attributed to $=\mathrm{C}-\mathrm{H}$ bending vibration (Samanta et al. 2020). The IR bands at 2915 and $2847 \mathrm{~cm}^{-1}$ in the untreated sample disappeared when the sample was treated with $P$. flavidoalba KH2_1). In addition, new peaks appeared at $1737,1433,1365$, and $1215 \mathrm{~cm}^{-1}$ corresponding to the $\mathrm{C}=\mathrm{O}$ stretching of aldehyde (1730 to $1720 \mathrm{~cm}^{-1}$ ), O-H bending, wagging deformation (Gulmine et al. 2002), and C-O stretching of ether group (Gajendiran et al. 2016), respectively. The detection of carbonyl and ether groups on the LDPE film proved that oxidation reactions occurred, providing evidence of potential biodegradation of the polymer. It is also important to note that the presence of carbonyl and ether groups could promote the biodegradation process of the polymer (Gilan et al. 2004; Sivan et al. 2006). The same IR bands in untreated LDPE films were observed for $S$. commune (DLP_1) and $P$. chrysosporium (DBP) treated samples with low transmittance values. In addition, new peaks appeared at 1648 and $1572 \mathrm{~cm}^{-1}$, indicating the formation of new $\mathrm{C}=\mathrm{C}$ bonds $(1500$ to $1680 \mathrm{~cm}^{-1}$ for $\mathrm{C}=\mathrm{C}$ stretching) when the samples were treated with $S$. commune (DLP_1) and $P$. chrysosporium (DBP). The most prominent changes were observed in the $P$. flavidoalba (KH2_1) treated sample (Fig. 3 A).

Preliminary investigations found that there were no noticeable differences in spectra when samples were taken from the middle or from the edge of the polyethylene sheets. Therefore, samples were taken from the LDPE sheets randomly for the analysis,

Perera et al. (2021). "Fungal polyethylene degraders," BioResources 16(4), 7056-7070. 7063 
and at least two to three repeated readings were taken per sample. There were no major deviations in the repeated analysis of each treatment.

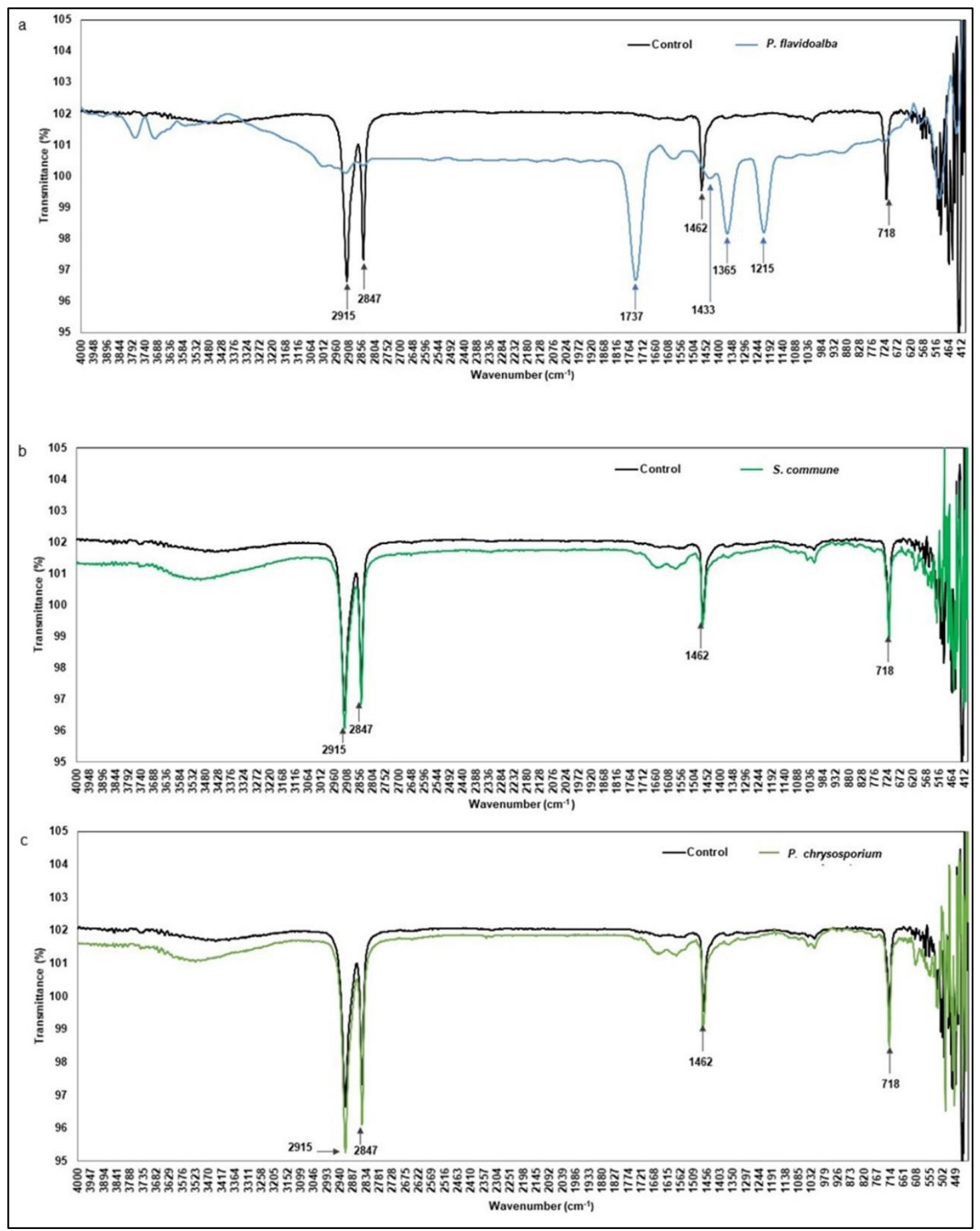

Fig. 3. FTIR spectra of LDPE after 60-day incubation with (a) Phlebiopsis flavidoalba (KH2_1), (b) Schizophyllum commune (DLP_1) and (c) Phanerodontia chrysosporium (DBP) compared with the controls shown in black. Untreated LDPE sheets showed peaks at $2915 \mathrm{~cm}^{-1}, 2847 \mathrm{~cm}^{-1}$, $1462 \mathrm{~cm}^{-1}$, and at $718 \mathrm{~cm}^{-1}$ attributing to various functional groups of polyethylene. 
Carbon dioxide evolution tests were reported to be difficult to perfom since they detect the $\mathrm{CO}_{2}$ levels indirectly (Strotmann et al. 2004). However, determination of percentage weight loss is a simple and fast method to assess the polymer degradation, which indicates the loss of polymer integrity (Gajendiran et al. 2016) and enzymatic hydrolysis of easily accessible side chains of polymers during the early stages of polyethylene biodegradation (Montazer et al. 2020). Weight loss has been used as an indicator of polyethylene degradation by various organisms such as wax moth, Galleria mellonella (Bombelli et al. 2017), and fungal and bacterial species (Muhonja et al. 2018). In the present study, there was a significant difference $(\mathrm{p}<0.05)$ in percent weight reduction among the different treatments. Percent weight loss ranged from $2.5 \%$ to $9.65 \%$ in three treatments, and the weight of the control remained constant (Table 2). Although $P$. flavidolba (KH2_1) showed remarkable results in FTIR analysis, the highest percent weight reduction resulted by $S$. commune (DLP_1).

Changes in mechanical properties are direct evidence of the degradation of a material. Maximum tensile stress (maximum stress that a material can tolerate before breaking apart), tensile stress at yield (a point at which it will no longer return to its original dimensions), and reduction or percent reduction in these properties are used in determining polyethylene degradation (Sangale et al. 2012; Awasthi et al. 2017; Bombelli et al. 2017; Samanta et al. 2020). During the present experiment, the control remained constant, and there was a significant difference among treatments for percent reduction in tensile stress and percent reduction in tensile stress at yield $(\mathrm{p}<0.05)$. Phlebiopsis flavidoalba $\left(\mathrm{KH} 2 \_1\right)$ had the highest percent reduction in both of these mechanical properties (Fig. 4), whereas the least reduction was observed for $P$. chrysosporium (DBP).

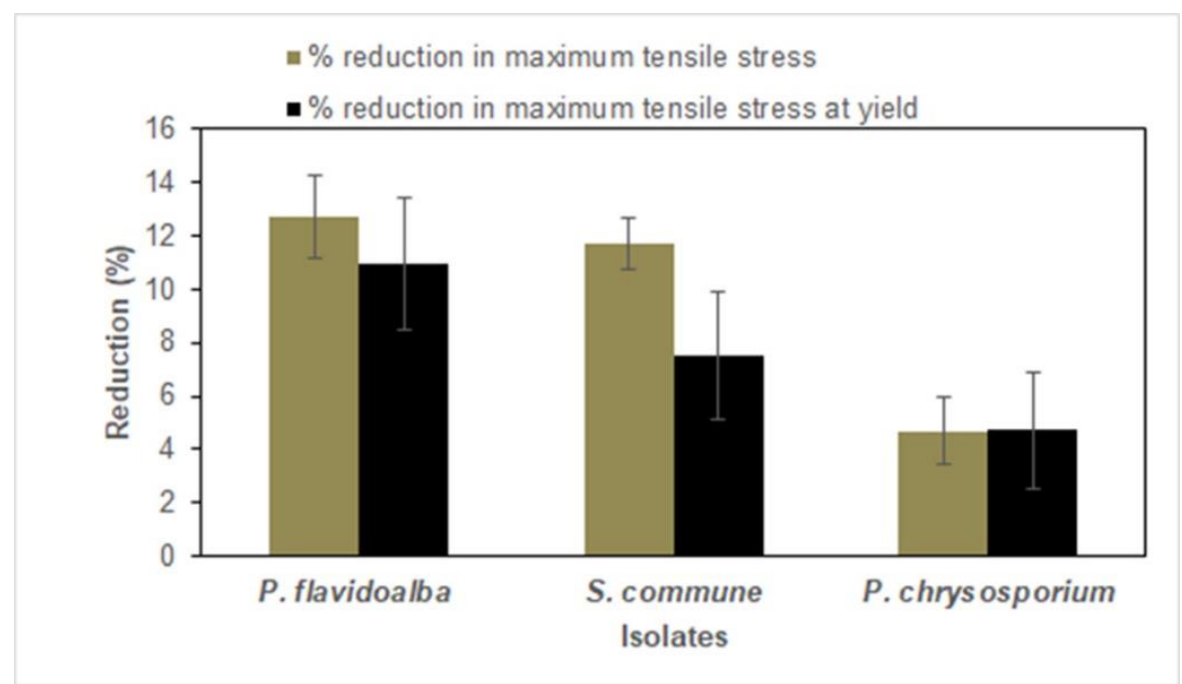

Fig. 4. Reduction in mechanical properties, percent reduction in maximum tensile stress and percent reduction in tensile stress at yield, of each 20 micron LDPE stripes treated with, Phlebiopsis flavidoalba (KH2_1), Schizophyllum commune (DLP_1) and Phanerodontia chrysosporium (DBP) after 60-day incubation period. Whiskers show one standard error.

Young's Modulus values of LDPE films indicated that the homogeneity of the LDPE was affected by the treatments, as noted by Samanta et al. (2020). The highest Young's modulus was observed for the control, suggesting that the highest stress is required to stretch the LDPE sheets compared with the other treatments. The lowest 
Young's modulus was observed for the sample treated with P. flavidoalba (KH2_1), and it was a 1.5 times reduction compared with the control.

SEM analysis also provided solid evidence of polyethylene degradation. The control sample had a smooth surface without any cracks, pits, or particles (Fig. 5A). In contrast, cracking, peeling, and holes or pits were clearly observed in randomly selected segments of LDPE sheets incubated with the fungal species (Fig. 5). Though it was not possible to quantify the size and numbers of such cavities, the cracks and holes were frequently observed in the sample treated with P. flavidoalba. Moreover, fungal mycelia were noticed on the film surface, indicating adherence of the mycelia to the LDPE sheets (Fig. 5E). Several studies have reported the formation of cavities, adherence of fungal mycelia and spores on the polyethylene films, and hyphal penetration during polyethylene biodegradation (Manzur et al. 2004; Awasthi et al. 2017; Ojha et al. 2017). Awasthi et al. (2017) reported that the initial step of polyethylene biodegradation is microbial adhesion to the polymer surface by secreting extracellular polymers.
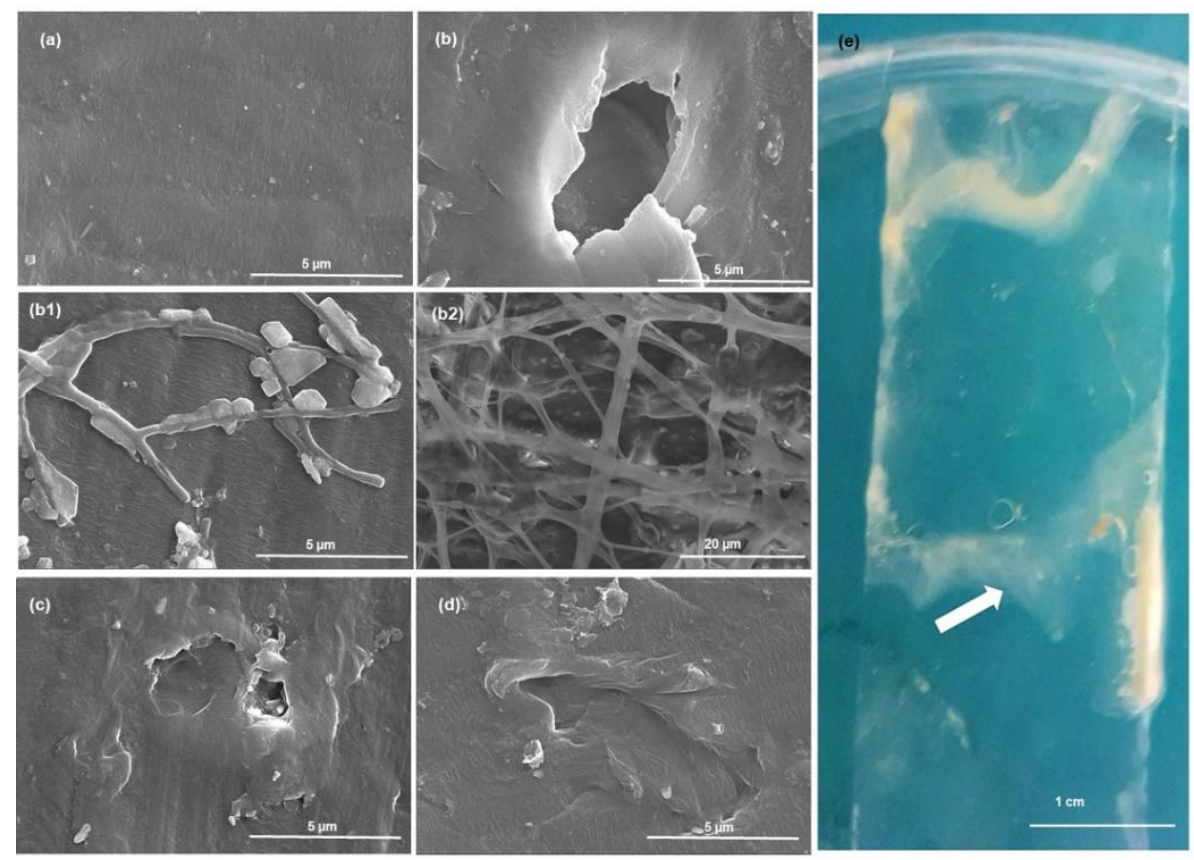

Fig. 5. Scanning electron microscopy of the LDPE sheets after 60 days incubation. (a) Control, (b) Phlebiopsis flavidoalba (KH2_1) treated LDPE sheets, (b1, b2) P. flavidoalba mycelia on LDPE sheets, (c) Schizophyllum commune (DLP_1), and (d) Phanerodontia chrysosporium (DBP) treated LDPE sheets and, (e) indications of mycelial growth on LDPE sheets.

\section{CONCLUSIONS}

1. LDPE sheet degradation was inferred by the FTIR analysis, weight loss, percent reduction in tensile properties, and SEM data.

2. The basidiomycete fungi Phlebiopsis flavidoalba, Schizophyllum commune, and Phanerodontia chrysosporium showed signatures of polyethylene degradation. Phlebiopsis flavidoalba and S. commune showed the most promising results in degrading LDPE sheets under in vitro conditions. 


\section{ACKNOWLEDGMENTS}

Funding from the TWAS research grant 18-020 RG/BIO/AS_I and ICGEB research grant CRP/LKA18-03 is acknowledged. Funding for the research student was provided by the National Science Foundation, Sri Lanka (NSF/RG/2019/BT/03).

\section{REFERENCES CITED}

Awasthi, S., Srivastava, N., Singh, T., Tiwary, D., and Mishra, P. K. (2017).

"Biodegradation of thermally treated low density polyethylene by fungus Rhizopus oryzae NS 5," 3 Biotech 7(1), 73. DOI: 10.1007/s13205-017-0699-4.

Chiellini, E., Corti, A., and Swift, G. (2003). "Biodegradation of thermally-oxidized, fragmented low-density polyethylenes," Polym. Degrad. Stabil. 81(2), 341-351. DOI: 10.1016/s0141-3910(03)00105-8.

Cortina-Escribano, M., Veteli, P., Riikka, L., Miina, J., and Vanhanen, H. (2020). "Effect of wood residues on the growth of Ganoderma lucidum," Karstenia 58(1), 16-28. DOI: $10.29203 / \mathrm{ka} .2020 .486$.

Das, M. P., and Kumar, S. (2015). "An approach to low-density polyethylene biodegradation by Bacillus amyloliquefaciens," 3 Biotech 5(1), 81-86. DOI: 10.1007/s13205-014-0205-1

Gajendiran, A., Krishnamoorthy, S., and Abraham, J. (2016). "Microbial degradation of low-density polyethylene (LDPE) by Aspergillus clavatus strain JASK1 isolated from landfill soil," 3 Biotech 6(1), DOI: 10.1007/s13205-016-0394-x.

Gajendiran, A., Krishnamoorthy, S., and Abraham, J. (2016). "Microbial degradation of low-density polyethylene (LDPE) by Aspergillus clavatus strain JASK1 isolated from landfill soil", 3 Biotech, 6(1), 52. DOI 10.1007/s13205-016-0394-X

Gilan, I., Hadar, Y., and Sivan, A. (2004). "Colonization, biofilm formation and biodegradation of polyethylene by a strain of Rhodococcus ruber," Appl. Microbiol. Biotechnol. 65, 97-104.

Gu, J. D. (2003). "Microbiological deterioration and degradation of synthetic polymeric materials: recent research advances," Int. Biodeterior. Biodegradation 52(2), 69-91. DOI: $10.1016 / \mathrm{S} 0964-8305(02) 00177-4$.

Gulmine, J., Janissek, P., Heise, H., and Akcelrud, L. (2002). "Polyethylene characterization by FTIR," Polym. Test. 21(5), 557-563. DOI: 10.1016/s01429418(01)00124-6.

Hall, T. A. (1999). "BioEdit: A user-friendly biological sequence alignment editor and analysis program for Windows 95/98/NT," Nucleic Acids Symposium Series 41, 9598.

Han, M. L., An, Q., Ma, K. Y., An, W. N., Hao, W. Y., Liu, M. Y., Shi, W. Y., Yang, J., and Bian, L. S. (2021). "A comparative study on the laccase activity of four Basidiomycete fungi with different lignocellulosic residues via solid-state fermentation," BioResources 16(2), 3017-3031. DOI: 10.15376/biores.16.2.30173031

Hatakka, A. (1994). "Lignin-modifying enzymes from selected white-rot fungi: production and role from in lignin degradation," FEMS Microbiol. Rev. 13(2-3), 125135.

Iiyoshi, Y., Tsutsumi, Y., and Nishida, T. (1998). "Polyethylene degradation by lignin- 
degrading fungi and manganese peroxidase," J. Wood Sci. 44(3), 222-229. DOI: $10.1007 /$ bf 00521967.

Jung, M. R., Horgen, F. D., Orski, S. V., Rodriguez C., V., Beers, K. L., Balazs, G. H., Jones, T. T., Work, T. M., Brignac, K. C., Royer, S. J., Hyrenbach, K. D., Jensen, B. A., and Lynch, J. M. (2018). "Validation of ATR FT-IR to identify polymers of plastic marine debris, including those ingested by marine organisms," Mar. Pollut. Bull. 127, 704-716. DOI: 10.1016/j.marpolbul.2017.12.061

Kang, B. R., Kim, S. B., Song, H. A., and Lee, T. K. (2019). “Accelerating the biodegradation of high-density polyethylene (HDPE) using Bjerkandera adusta TBB03 and lignocellulose substrates," Microorganisms 7(9), 304. DOI:

10.3390/microorganisms7090304.

Kiiskinen, L. L., Kruus, K., Bailey, M., Ylösmäki, E., Siika-aho, M., and Saloheimo, M. (2004). "Expression of Melanocarpus albomyces laccase in Trichoderma reesei and characterization of the purified enzyme," Microbiology 150(9), 3065-3074. DOI: 10.1099/mic.0.27147-0.

Kirk, T. K., and Farrell, R. L. (1987). "Enzymatic 'combustion': The microbial degradation of lignin," Annu. Rev. of Microbiol 41(1), 465-501. DOI: 10.1146/annurev.mi. 41.100187.002341

Krueger, M. C., Hofmann, U., Moeder, M., and Schlosser, D. (2015). "Potential of woodrotting fungi to attack polystyrene sulfonate and its depolymerisation by Gloeophyllum trabeum via hydroquinone-driven fenton chemistry," PloS One 10(7), e0131773. DOI: 10.1371/journal.pone.0131773

Kumar, A., and Chandra, R. (2020). "Ligninolytic enzymes and its mechanisms for degradation of lignocellulosic waste in environment," Heliyon 6(2), e03170. DOI: 10.1016/j.heliyon. 2020.e03170

Maduranga, K., Attanayake, R. N., Santhirasegaram, S., Weerakoon, G., and Paranagama, P. A. (2018). "Molecular phylogeny and bioprospecting of Endolichenic Fungi (ELF) inhabiting in the lichens collected from a mangrove ecosystem in Sri Lanka," PlosOne 13(8), e0200711. DOI: 10.1371/ journal.pone.0200711

Mahalakshmi, V., Siddiq, A., and Andrew, S. N. (2012). "Analysis of polyethylene degrading potentials of microorganisms isolated from compost soil," IJPBA 3(5), 1190-1196.

Mate, D. M., and Alcalde, M. (2016). "Laccase: A multi-purpose biocatalyst at the forefront of biotechnology," Microbial Biotechnology 10(6), 1457-1467. DOI: 10.1111/1751-7915.12422

Mathur, G., Mathur, A., and Prasad, R. (2011). "Colonization and degradation of thermally oxidized high-density polyethylene by Aspergillus niger (ITCC No. 6052) isolated from plastic waste dumpsite," Bioremediat. J. 15(2), 69-76. DOI: 10.1080/10889868.2011.570281

Montazer, Z., Mohammad, B., Najafi, H., and Levin, D. B. (2020). "Challenges with verifying microbial degradation of polyethylene," Polym. 12(1), 123. DOI: 10.3390 /polym 12010123

Muhonja, C.N., Makonde, H., Magoma, G., and Imbuga, M. (2018). "Biodegradability of polyethylene by bacteria and fungi from Dandora dumpsite Nairobi-Kenya," PlosOne 13(7), e0198446. DOI: 10.1371/journal.pone.0198446 
Nicolcioiu, M. B., Popa, G., and Matei, F. (2018). "Biochemical investigations of different mushroom species for their biotechnological potential," in: Proceedings of the Agriculture for Life, Life for Agriculture, Bucharest, Romania, pp. 562-567. DOI: 10.2478/alife-2018-0088

Nilsson, R. H., Larsson, K-H., Taylor, A. F. S., Bengtsson-Palme, J., Jeppesen, T. S., Schigel, D., Kennedy, P., Picard, K., Glöckner, F. O., Tedersoo, L. et al. (2019). "The UNITE database for molecular identification of fungi: Handling dark taxa and parallel taxonomic classifications," Nucleic Acids Res. 47, D259-D264. DOI: 10.1093/nar/gky1022

Ojha, N., Pradhan, N., Singh, S., Barla, A., Shrivastava, A., Khatua, P., Rai, V., and Bose, S. (2017). "Evaluation of HDPE and LDPE degradation by fungus, implemented by statistical optimization," Sci. Rep. 7, 1-13. DOI: 10.1038/srep39515

Ravichandran, A., Rao, R. G., Thammaiah, V., Gopinath, S. M., and Sridhar, M. (2019).

"A versatile peroxidase from Lentinus squarrosulus towards enhanced delignification and in-vitro digestibility of crop residues," BioResources 14(3), 5132-5149. DOI: 10.15376/biores.14.3.5132-5149

Rodgers, C. J., Blanford, C. F., Giddens, S. R., Skamnioti, P., Armstrong, F. A., and Gurr, S. J. (2010). "Designer laccases: A vogue for high-potential fungal enzymes?," Trends Biotechnol. 28(2), 63-72. DOI: 10.1016/j.tibtech.2009.11.001.

Romero, E., Speranza, M., GarcÃa-Guinea, J., MartÃnez, N. T., and MartÃnez, M. J. (2007). "An anamorph of the white-rot fungus Bjerkandera adusta capable of colonizing and degrading compact disc components," FEMS Microbiol. Letters 275(1), 122-129. DOI: 10.1111/j.1574-6968.2007.00876.x

Samanta, S., Datta, D., and Halder, G. (2020). "Biodegradation efficacy of soil inherent novel sp. Bacillus tropicus (MK318648) onto low density polyethylene matrix," J. of Polym. Res. 27(10). DOI: 10.1007/s10965-020-02296-X

Sangale, M. K., Shahnawaz, M. and Ade, A. B. (2012). "A review on biodegradation of polythene: The microbial approach," J. Bioremed. Biodeg. 3(10), 1-9.

Santo, M., Weitsman, R., and Sivan, A. (2013). "The role of the copper-binding enzymelaccase-in the biodegradation of polyethylene by the actinomycete Rhodococcus ruber," Int. Biodeter. Biodegr. 84, 204-210.

Schoch, C. L., Seifert, K. A., Huhndorf, S., Robert, V., Spouge. J. L., Levesque, C. A. and Chen, W. (2012). "Nuclear ribosomal internal transcribed spacer (ITS) region as a universal DNA barcode marker for fungi," Proc. Natl. Acad. Sci. 109(16), 6241-6246.

Sivan, A., Szanto, M., and Pavlov, V. (2006). "Biofilm development of the polyethylene degrading bacterium Rhodococcus ruber," Appl. Microbiol. Biotechnol. 72, 346-352.

Spina, F., Tummino, M. L., Poli, A., Prigione, V., Ilieva, V., Cocconcelli, P., Puglisi, E., Bracco, P., Zanetti, M., and Varese, G. C. (2021). "Low density polyethylene degradation by filamentous fungi," Environ. Pollut. 274, 116548. DOI: 10.1016/j.env pol.2021.116548

Strotmann, U., Reuschenbach, P., Schwarz, H., and Pagga, U. (2004). "Development and evaluation of an online $\mathrm{CO}_{2}$ evolution test and a multicomponent biodegradation test system," Appl. Environ. Microbiol. 70(8), 4621-4628. DOI:10.1128/AEM.70.8.46214628.2004 
White, T. J., Bruns, T. D., Lee, S. B., and Taylor, J. W. (1990). “Amplification and direct sequencing of fungal ribosomal RNA Genes for phylogenetics," in: PCR Protocols: A Guide to Methods and Applications, M. A. Innis, D. H. Gelfand, J. J. Sninsky, and T. J. White (eds.), Academic Press, New York, pp. 315-322. DOI: 10.1016/B978-0-12372180-8.50042-1

Article submitted: May 14, 2021; Peer review completed: August 10, 2021; Revised version received and accepted: August 31, 2021; Published: September 3, 2021.

DOI: $10.15376 /$ biores.16.4.7056-7070 